\title{
TRANSITORY SYNOVITIS OF THE HIP IN CHILDREN
}

\author{
K. L. G. MILls, M.A., B.Sc., F.R.C.S. \\ Aberdeen Royal Infirmary
}

Transitory synovitis is a condition of unknown ætiology affecting the hips of children under the age of I4. It is characterized by the sudden onset of pain in the joint with limitation of movement. It is not clearly related to trauma. There are rarely any radiological changes, and other investigations are essentially normal. The condition spontaneously regresses and no specific treatment is known.

The condition was first noted by Todd (1925) and Fairbank (1926). It has also been called coxitis fugax, coxitis serosa, irritable hip and observation hip. Butler wrote about the condition in 1933, differentiating it from tuberculosis but since then it has seldom been mentioned in British journals (McMurray, 1947; Caravias, I956; de Valderrama, I963; Adams, 1963). Miller(1931) reported 77 cases from the U.S.A. and suggested that synovitis of the hip was secondary to small epiphyseal abscesses. He found a focus of infection elsewhere in all his cases, but he did not aspirate any of the hips. Finder (1936) followed 20 cases for an unrecorded period and reported no untoward sequelæ. Rauch (1940) published another series of 37 cases reporting recurrent attacks and suggesting an increased incidence in spring and summer. Ten American authors in the 1950's reported series of cases but many of their children were not admitted to hospital, nor were they fully investigated. Spock (1959) noted that the condition is rarely reported in negroes.

Most authors report a preponderance of males, the hips being equally affected. Simultaneous involvement of both hips has not been reported nor has simultaneous involvement of other joints. The commonest age range is 4 to 8 years with a scatter from I to I4. A seasonal variation is reported by Rauch (1940) and Ebert (1960). The onset of pain is frequently sudden and often at night. There is limitation of movement of the affected hip. Radiographs show only soft tissue swelling around the joint (Drey 1953). There is rarely any great disturbance of temperature, sedimentation rate or white cell count. Most authors treat their patients by bed rest and traction. Recovery within a few weeks is the rule. Butler (1933) said he followed his $19 \vec{\omega}$ cases for $3 \frac{1}{2}$ years while he and Finder (1936) report no sequelæ. Fox (1956) reported 2 caseso of coxa plana from 9 patients while Spock (1959) reported 2 cases from $4 \mathrm{I}$-but these 4 cases of 0 coxa plana are an entirely separate condition. Tudor (1960) said he followed his 118 cases for up to ro years and found no case of coxa plana. $\vec{\varnothing}$ Nevertheless de Valderrama (1963) surveyed 230 patients $I 5$ to 30 years after their illness and found varying degrees of coxa magna, osteoarthritis $\overrightarrow{-}$ or simple broadening of the femoral neck in 12 of these. Adams (1963) in a shorter follow. up of a smaller number of cases found no evidenges that transient synovitis led to later avascutgir. changes in the femoral head.

There is some speculation as to the cause this condition. Most authors favour an infective cause-an infection in the upper respiratory tract leading to a metastasis or an allergic reaction $\frac{\Omega}{\Omega}$ in the hip. However, only Spock (1959) quotes $\vec{F}$ any results from throat swabs; one-third of his 3 cases produced hæmolytic streptococci. Trauma is a second possible cause but the numbers who recall recent trauma are not convincing. Allergy is a third suggested causative factor but there 3 . is no definite evidence, while Tudor (1960) says he has seen no case of synovitis of the hip in 400 allergic children.

\section{Present Series}

This paper is a review of 96 cases admitted to the Royal Aberdeen Hospital for Sick Children in the 10 year period $195 \mathrm{I}-1960$ with a report of the present condition of 81 of them. The hospital admits children only up to the age of ${ }_{0}$ 12 years. I05 cases were admitted with an initial ${ }_{\omega}^{N}$ diagnosis of irritable hip but 9 were discardedo when investigations proved another condition too be present (including coxa plana). During this decade there were admitted 34 cases of coxa? plana, I I tuberculous hips, 28 septic arthritis 0 and 3 slipped upper femoral epiphyses. In addition, 86 children with transient synovitis of the hip were seen as out-patients, and treated at $\stackrel{\mathrm{D}}{\Omega}$ 
TABLE I

Numbers Each Year

$\begin{array}{cccccccc}1951 & 1952 & 1953 & 1954 & 1955 & 1956 & 1957 & 1958 \\ 6 & 16 & 7 & 9 & 6 & 5 & 13 & 14 \\ & & & 1959 & 1960 & & & \\ & & & 9 & 11 & & & \end{array}$

\section{Numbers Each Month}

Jan. Feb. Mar. April May June July Aug.

$\begin{array}{cccccccc}7 & 4 & 9 & 10 & 16 & 9 & 4 & 10 \\ & & \text { Sept. } & \text { Oct. } & \text { Nov. } & \text { Dec. } & & \\ 9 & 7 & 8 & 12 & & \end{array}$

Numbers Per Year of Follow-up

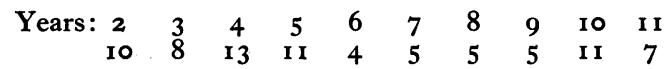

home. These children are not included in the series under review as they were not all fully investigated. Within the group of 96 admissions there was no seasonal incidence, nor was there a concentration of cases in any one year. The numbers are not large enough for there to be any statistical significance in the variation shown. (See Table r.)

There were more males than females, 71 to 25 (See Table 2). The right hip was affected in 57 cases, the left in 39. The age range was 9 months to 12 years but 64 cases fell in the range 3 to 7 years. 79 children presented with pain but 3 of these complained only of a painful knee. Only I 5 patients had symptoms lasting for more than 3 weeks before admission but the average duration was 5 days. 6 children had suffered previous attacks of pain in the same hip of a similar nature. 22 children had suffered recent minor trauma. 14 had had recent colds or sore throats and 2 were said to be allergic. 30 children had some degree of fixed flexion. The temperature was raised in 44 cases, but in only 13 was it over $100^{\circ} \mathrm{F}$. $\left(3^{\circ} \mathrm{C}\right.$.). The E.S.R. was raised in 19 children and in 2 was $50 \mathrm{~mm} /$ hour. The Mantoux reaction was negative in 60 and positive in 2-the average for Aberdeen children in this age group. The white cell count was raised in 17.22 initial $\mathrm{X}$-rays showed some soft tissue swelling around the hip and I I some decalcification. The treatment of 73 children consisted of bed rest and traction to the affected leg. I7 of these received antibiotics (usually penicillin) and it may be argued that the administration of such substances obscures a diagnosis of transient synovitis. However, this group of patients was not distinguished by any particular clinical feature and the prescription of their antibiotic seemed to depend on no clearly defined reason. The mean period in hospital for the whole group of 96 children was I9 days. However, 2 patients took
TABLE 2

Clinical Features

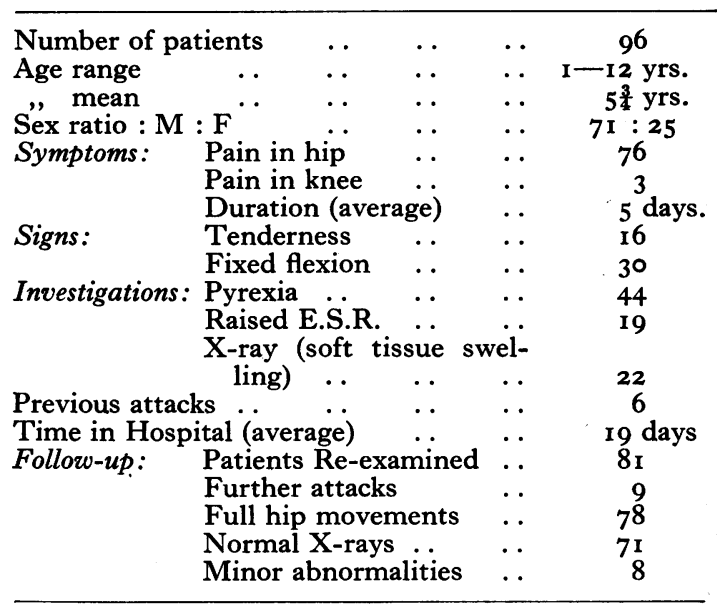

TABLE 3

Radiographic Abnormalities

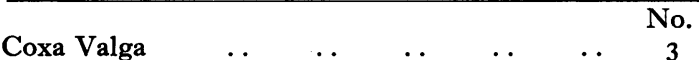

Osteochondromata of inferior pubic rami $\quad \cdots \quad 3$

Localised central acetabular depression opposite a deep fovea .. $\quad \ldots \quad \ldots \quad \ldots \quad 3$

very long periods to become pain free (70 and 98 days). There was no obvious cause for this.

In the summer of 1962,81 of these children were traced and examined. The follow-up period ranged from 2 to I I years (See Table I). Nine patients reported further attacks of pain in the hip but only 2 were readmitted to hospital. All recurrent attacks affected the same hip. Only 7 patients admitted to any sort of allergy and only 7 suffered from repeated upper respiratory tract infections. All but 3 patients had full hip movements and these 3 were but slightly restricted and had no radiographic abnormality of their hips. 79 patients were X-rayed and $7 \mathrm{I}$ were found to be completely normal. The 8 minor abnormalities are listed in Table 3 and are not thought to be due to preceding synovitis.

\section{Discussion}

Transitory synovitis of the hip is important in that it may precede serious damage to the joint from a variety of causes, yet itself appears to be a benign condition of unknown ætiology. It poses some unanswered questions. Why does it affect the hip in preference to other joints? Why is only one hip affected in the initial attack and the same hip in the uncommon re- 
current attack? If infection is the cause, then remarkably few children are affected. However, the relationship of upper respiratory tract infections to transient synovitis requires further investigation. The age of maximum incidence of upper respiratory tract infections and synovitis of the hip coincides, thus leading to some difficulty in deciding the significance of coincident infections. New cases of transient synovitis would have to be matched with children of the same age, sex and environment, both being bacteriologically investigated. Aspiration of synovial fluid may be helpful in determining ætiology but this investigation may be ethically unjustifiable in a benign 'condition. Moreover, an effusion may not be invariable as the hip does not always take up the position of maximum capacity of the joint. The preponderance of boys may be significant of either their greater liability to trauma or their genetic constitution. However, boys and girls attend with minor trauma in equal numbers at the Casualty Department of the Royal Aberdeen Hospital for Sick Children.

No patients have had their allergic status investigated and this may be a useful line of future enquiry. Some children have been treated by anti-histamines (Fox 1956) and some with steroids (Rotheschild 1956). The rapid recovery of these patients does not prove their treatment to have been especially efficacious.

Transitory synovitis in itself is a relatively trivial condition but its importance lies in thos other conditions the early stages of which if mimics, i.e. tuberculosis of the hip, septic arthritis of the hip, coxa plana, slipped upper femorat epiphysis in older children, rheumatic fever and juvenile rheumatoid arthritis. These possibilitis must always be considered before a definite diagnosis of transitory synovitis is made. The child with synovitis always has a limp, pain of movement and a limited range of movemer (fixed flexion of the hip is probably more commom than has been noted). There are minimal temperature and blood changes. There are no bony changes on X-ray although soft tissue swelling may be visible. The child's rapid recovery wit bed rest and traction is characteristic.

\section{Summary}

A series of 96 children with transient synovitis of the hip is described. $8 \mathrm{I}$ of these have bea examined recently and underwent radiograplम of the hips. The follow-up interval was 2 to $\mathrm{P}$ years. 6 children had previous attacks of pain the same hip and 9 had subsequent attacks, again in the same hip. No long term ill effects were discovered and no child developed coxa plana or coxa magna. The literature is surveyed and possible ætiological factors discussed. differential diagnosis is emphasized.

My thanks are due to Mr. I. G. Mackenzie for the and encouragement and to $\mathrm{Mr}$. A. Adam for criticisr

\section{REFERENCES}

Adams, J. A. (1963): Transient Synovitis of the Hip Joint in Children, $\mathcal{F}$. Bone Ft. Surg., 45B, 47 r.

Butler, R. W. (1933): Transitory Arthritis in the Hip Joint in Children, Brit. med. F., i, 95I.

Caravias, D. E. (1956): The Significance of the So-called Irritable Hips in Children, Arch. Dis. Child., 31, 41 5.

De Valderrama, J. A. F. (1963): The 'Observation Hip' Syndrome and its Late Sequelæ, F. Bone Ft. Surg., 45B, 46:

DREY, L. (I953): Rœntgenographic Study of Transitory Synovitis, Radiology, 60, 588.

Ebert, G., Lechten, K. A. (1960): Transitory Synovitis of the Hip Joint in Children, Dtsch. med. Wschr., 85, 2 I 13.

Fairbank, H. A. T. (1926): Discussion of Non-tuberculous Coxitis in the Young, Brit. med. $\mathcal{F}$., ii, 828.

Finder, J. E. (1936): Transitory Arthritis in Hip Joint in Childhood, $\mathscr{Y}$. Amer. med. Ass., 107, 3.

Fox, K. W., Griffin, L. L. (1956): Transient Synovitis of the Hip Joint in Children, Tex. St. F. Med., 52, I 5.

McMurray, B. (1947): A Report of Six Cases of Coxa Magna following Synovitis of the Hip, Brit. F. Radiol., 20, 4

Miller, O. L. (1931): Acute Transient Epiphysitis of Hip Joint, F. Amer. med. Ass., 96, 575.

RauCH, S. (1940): Transitory Arthritis in Hip Joint in Childhood, Amer. F. Dis. Child., 59, 1245.

Rothschild, H. B., Russ, J. D., and Wasserman, C. F. (1956): Corticotrophins in the Treatment of Transient Synovitis of the Hip in Children, F. Pediat., 49, 33.

Spock, A. (1959): Transient Synovitis of the Hip Joint in Children, Pediatrics, $24,1042$.

Todd, A. H. (1925): Proc. roy. Soc. Med., r8, (Sect. Orthop.), 3 I.

Tudor, R. B. (1960): Hip Synovitis in Children, F.-Lancet, 80, 51 . 